\title{
Knowledge, Attitude and Practice of Dietary and Lifestyle Habits Among Medical Students in King Abdulaziz University, Saudi Arabia
}

\author{
Eman Mokbel Alissa ${ }^{1,2, ~ *}$, Hend Alsawadi ${ }^{3}$, Asma Zedan $^{3}$, Dalya Alqarni ${ }^{3}$, Maria Bakry $^{3}$, \\ Nojoud Bin $\mathrm{Hli}^{3}$ \\ ${ }^{1}$ Department of Clinical Biochemistry, Faculty of Medicine, King Abdulaziz University, Jeddah, Saudi Arabia \\ ${ }^{2}$ Head of Elemental Spectroscopy Unit, King Fahd Medical Research Center, King Abdulaziz University, Jeddah, Saudi Arabia \\ ${ }^{3}$ Faculty of Medicine, King Abdulaziz University, Jeddah, Saudi Arabia
}

\author{
Email address: \\ em_alissa@yahoo.com (E. M. Alissa)
}

\section{To cite this article:}

Eman Mokbel Alissa, Hend Alsawadi, Asma Zedan, Dalya Alqarni, Maria Bakry, Nojoud Bin Hli. Knowledge, Attitude and Practice of Dietary and Lifestyle Habits Among Medical Students in King Abdulaziz University, Saudi Arabia. International Journal of Nutrition and Food Sciences. Vol. 4, No. 6, 2015, pp. 650-655. doi: 10.11648/j.ijnfs.20150406.18

\begin{abstract}
Knowing the medical students' knowledge, attitude and practices of nutritional and lifestyle habits helps to enhance the nutrition of the community, which will consequently lead to a healthier society, as they will constitute the main body of future physicians and professionals. We aimed to evaluate their nutrition knowledge, their eating habits and overall perception regarding importance of healthy eating habits of medical students of King Abdulaziz University, Kingdom of Saudi Arabia. A cross-sectional study included 200 students between ages 19-24 years from basic and clinical levels in the faculty of medicine. A self-reported questionnaire was employed to assess perceived attitude and barriers to healthy practices by the study participants. Overall most medical students were aware of the importance of healthy eating habits yet they were not practicing it adequately in their daily life. Improving nutrition knowledge, attitude and dietary practices through nutritional education may help to prevent many nutrition-related diseases.
\end{abstract}

Keywords: Knowledge, Attitude, Practice, Medical Students, Saudi Arabia

\section{Introduction}

Knowledge can influence health-related behaviors when informing attitudes, and beliefs [1]. Whilst it is acknowledged that nutrition forms an important part of health management, it has been reported that nutrition training of medical students is inadequate in both quality and quantity [2] [3].

It is often assumed that the medical students have a greater knowledge about healthy lifestyle and dietary habits when compared to non-medical students. However there is no evidence to indicate that this knowledge translates into maintaining good health practices [4]. Healthy dietary habits among medical students are even more important as they are future physicians and the students who personally ignore adopting healthy lifestyle are more likely to fail to champion health promotion opportunities for their patients. Many programs have shown that adoption of new behavior or modification of the existing behavior needs much input like knowledge, awareness of the matter, attitude, and perception. Most authors found that whilst behaviors are unlikely to change without an increase in knowledge, knowledge alone is insufficient to bring about significant improvement in preventive behavior [5]. Knowledge can however, influence health-related behaviors when mediated by attitudes, belief, self-efficacy, and an effective call to action [1] [6].

In the Kingdom of Saudi Arabia (KSA), there are few studies reflecting medical students knowledge and perception of healthy lifestyle habits including nutrition. In the present study we aimed to evaluate their nutrition knowledge, their eating habits and overall perception regarding importance of healthy eating habits of medical students of King Abdulaziz University (KAU), KSA. 


\section{Methods}

\subsection{Study Design}

A cross-sectional survey was conducted between March to August 2014. A convenience sample of 200 participants were selected from the medical students enrolled at King Abdulaziz University, Jeddah, KSA. Subjects being invited responded voluntarily. The students were informed about the purpose of the study and the method of completing the questionnaire. All participants provided informed written consent to a protocol approved by the local Ethical Review board of KAUH.

\subsection{Study Participants}

Inclusion criteria for respondents include: all male and female medical students, from basic science and clinical years, and were between 19-24 years old. Moreover, students with a clinically diagnosed chronic illness or on a prescribed medication, pregnant females and those outside the age bracket were excluded.

\subsection{Data Collection}

A self reported structured questionnaire was designed incorporating relevant questions from several studies [7] [8] [9]. There were a total of 31 questions, broadly divided into two categories of socio-demographics, personal medical history, family history of any disease, healthy dietary attitudes and lifestyle practices, barriers to healthy practices and knowledge assessment about healthy diet and lifestyle habits.

The second category focused on the assessment of their nutrition knowledge, attitude and practice regarding the importance of healthy eating habits, knowledge of the benefits of physical activity and barriers to healthy practices. The students can choose more than one answer based on the nature of the question.

The level of knowledge in nutrition was assessed by questions on nutrients value, nutrients characteristics and nutrients functions. The part on nutritional attitude and practice included questions about healthy diet, food selection and dining habits.

A pilot study was conducted first on a batch of 20 students. Based on the practical experience of the pilot study, food items listed in section 2 of the questionnaire were reduced to include the most frequently consumed junk foods and the most popular fast food brands.

\subsection{Statistical Analysis}

Data are expressed as mean \pm standard deviation for numeric variables and as frequency or proportion for categoric variables. Differences in means was assessed by student t-test or $\chi^{2}$ test for numeric and categoric variables respectively. All the analyses were done using the Statistical Package for Social Sciences (SPSS) version 20.0. All reported $\mathrm{P}$ values were two-tailed and $\mathrm{p}$ values $<0.05$ were considered statistically significant.

\section{Results}

Table (1). Nutritional knowledge among the study cohort $(N=200)$.

\begin{tabular}{|c|c|c|}
\hline & $\begin{array}{l}\text { No. }(\%) \text { of } \\
\text { respondents } \\
\text { answered correctly }\end{array}$ & $\begin{array}{l}\text { No. }(\%) \text { of } \\
\text { respondents } \\
\text { answered incorrectly }\end{array}$ \\
\hline $\begin{array}{l}\text { Composition of } \\
\text { balanced diet }\end{array}$ & $168(84)$ & 32 (16) \\
\hline $\begin{array}{l}\text { Identification of } \\
\text { healthy food }\end{array}$ & $60(30)$ & $140(70)$ \\
\hline $\begin{array}{l}\text { Healthy methods of } \\
\text { cooking }\end{array}$ & $36(18)$ & $164(82)$ \\
\hline $\begin{array}{l}\text { Identification of the } \\
\text { healthiest frying } \\
\text { method }\end{array}$ & 187 (94) & $13(6)$ \\
\hline $\begin{array}{l}\text { Identification of the } \\
\text { healthiest form of food } \\
\text { types }\end{array}$ & $149(75)$ & $51(25)$ \\
\hline $\begin{array}{l}\text { Importance of vitamins } \\
\text { and minerals } \\
\text { consumption }\end{array}$ & $149(75)$ & $51(25)$ \\
\hline $\begin{array}{l}\text { Meaning of organic } \\
\text { food }\end{array}$ & $152(77)$ & $48(23)$ \\
\hline $\begin{array}{l}\text { Meaning of genetically } \\
\text { modified food }\end{array}$ & 76 (39) & $124(61)$ \\
\hline
\end{tabular}

Table (2). Perceived benefits and barriers to physical exercises among the study cohort.

\begin{tabular}{|c|c|c|c|c|}
\hline & $\begin{array}{l}\text { All } \\
(\mathrm{N}=\mathbf{2 0 0})\end{array}$ & $\begin{array}{l}\text { Females } \\
(n=136)\end{array}$ & $\begin{array}{l}\text { Males } \\
(n=64) \\
\end{array}$ & $\mathbf{p}$ \\
\hline \multicolumn{5}{|l|}{ Perceived benefits } \\
\hline Promote and maintain health & $107(54)$ & $77(57)$ & $30(47)$ & \multirow{4}{*}{ NS } \\
\hline $\begin{array}{l}\text { Weight control and obesity } \\
\text { prevention }\end{array}$ & $59(30)$ & $36(27)$ & $23(36)$ & \\
\hline Recreation & $17(9)$ & $11(8)$ & $6(9)$ & \\
\hline Competition & $13(7)$ & $8(6)$ & $5(8)$ & \\
\hline \multicolumn{5}{|l|}{ Perceived barriers } \\
\hline Lack of time & $113(57)$ & $71(52)$ & $42(66)$ & \multirow{6}{*}{ NS } \\
\hline Lack of motivation & $48(24)$ & $33(24)$ & $15(23)$ & \\
\hline Lack of proper facilities & $22(11)$ & $19(14)$ & $3(5)$ & \\
\hline Health reasons & $5(3)$ & $2(2)$ & $3(5)$ & \\
\hline Not important & $12(6)$ & $11(8)$ & $1(2)$ & \\
\hline No barriers & $4(2)$ & $4(3)$ & $0(0)$ & \\
\hline
\end{tabular}

Table (3). Practices of healthy lifestyle by the study cohort.

\begin{tabular}{|c|c|c|c|c|}
\hline & $\begin{array}{l}\text { All } \\
(N=\mathbf{2 0 0})\end{array}$ & $\begin{array}{l}\text { Females } \\
(n=136)\end{array}$ & $\begin{array}{l}\text { Males } \\
(n=64)\end{array}$ & $\mathbf{p}$ \\
\hline \multicolumn{5}{|c|}{ Where do you do your physical activities? } \\
\hline Gym & $17(9)$ & $9(7)$ & $8(13)$ & \multirow{5}{*}{$<0.05$} \\
\hline Public open area & $13(7)$ & $2(2)$ & $11(17)$ & \\
\hline University campus & $18(9)$ & $16(12)$ & $2(3)$ & \\
\hline Home & $57(29)$ & $49(36)$ & $8(13)$ & \\
\hline More than one place & $68(34)$ & $45(33)$ & $23(36)$ & \\
\hline \multicolumn{5}{|c|}{ Daily use of stairs (1 floor counts as 1 time) } \\
\hline None & $10(5)$ & $8(6)$ & $2(3)$ & \multirow{4}{*}{ NS } \\
\hline 1-2times & $55(28)$ & $41(30)$ & $14(22)$ & \\
\hline 3-4times & $62(31)$ & $40(29)$ & $22(34)$ & \\
\hline$\geq 5$ times & $73(37)$ & $47(35)$ & $26(41)$ & \\
\hline \multicolumn{5}{|c|}{$\begin{array}{l}\text { Does your daily routine involve physical activity (that causes } \\
\text { small increases in breathing or heart rate ,e.g., brisk walking, for } \\
\text { at least } 10 \text { minutes continuously)? }\end{array}$} \\
\hline None & $99(50)$ & $68(50)$ & $31(48)$ & \multirow[t]{4}{*}{ NS } \\
\hline 1-3 times & $85(43)$ & $56(41)$ & $29(45)$ & \\
\hline 4-6 times & $13(7)$ & $9(7)$ & $4(6)$ & \\
\hline$\geq 7$ times & $3(2)$ & $3(2)$ & $0(0)$ & \\
\hline
\end{tabular}


A total of 200 students participated of which females were higher $(68 \%)$ compared to males $(32 \%)$. Sixty one percent were from basic years and $39 \%$ were from clinical years. The mean age for female and male student subgroups was $20.6 \pm$ 0.1 years and $21.2 \pm 0.1$ years respectively.

Nutritional knowledge of the study participants is summarized by their answers to eight questions in Table (1). Overall, $75 \%-94 \%$ of the students were aware of the composition of balanced diet, identification of the healthiest frying method, identification of the healthiest eating behavior, importance of vitamins and minerals consumption and the meaning of organic food. Only $18 \%-39 \%$ of students were aware of the healthy methods of cooking, identification of healthy food and the meaning of genetically modified food.

Table (2) shows perceived benefits and barriers to physical exercises among the study participants. Almost half of the students agree that physical exercises promote and maintain health whereas $57 \%$ of students think that lack of time is the main reason behind not exercising as they should be.
Nevertheless, no significant differences in perceived barriers and benefits were observed between male and female students $(\mathrm{p}>0.05)$.

Some practices of healthy lifestyle are presented in Table (3). About $45 \%$ of students responded that they practice physical exercises in more than one place, including the gym, university campus, public open areas and/or home. Regarding daily use of stairs (i.e., 1 floor counts as 1 time), $28 \%$ of the study cohort admitted to use them 1-2times, $31 \%$ used them 3-4times and they were used $\geq 5$ times by $37 \%$. When the students were questioned whether their daily routine involve physical activity (that causes small increases in breathing or heart rate ,e.g., brisk walking, for at least 10 minutes continuously), half of them responded by no, $43 \%$ said 1-3 times and very few answered 4-6 times and $\geq 7$ times. However, male and female students only showed significant difference in their whereabouts to perform physical exercises $(\mathrm{p}<0.05)$.

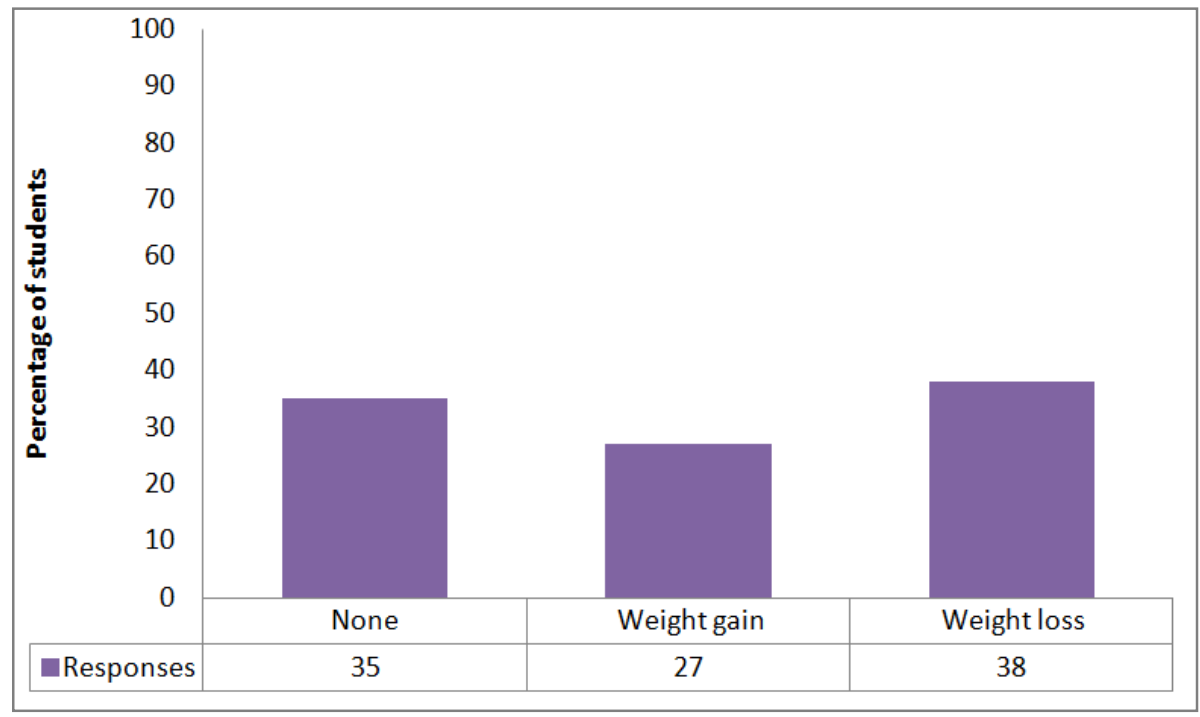

Figure (1). Responses frequency from the study cohort $(N=200)$ on weight fluctuation during last year.

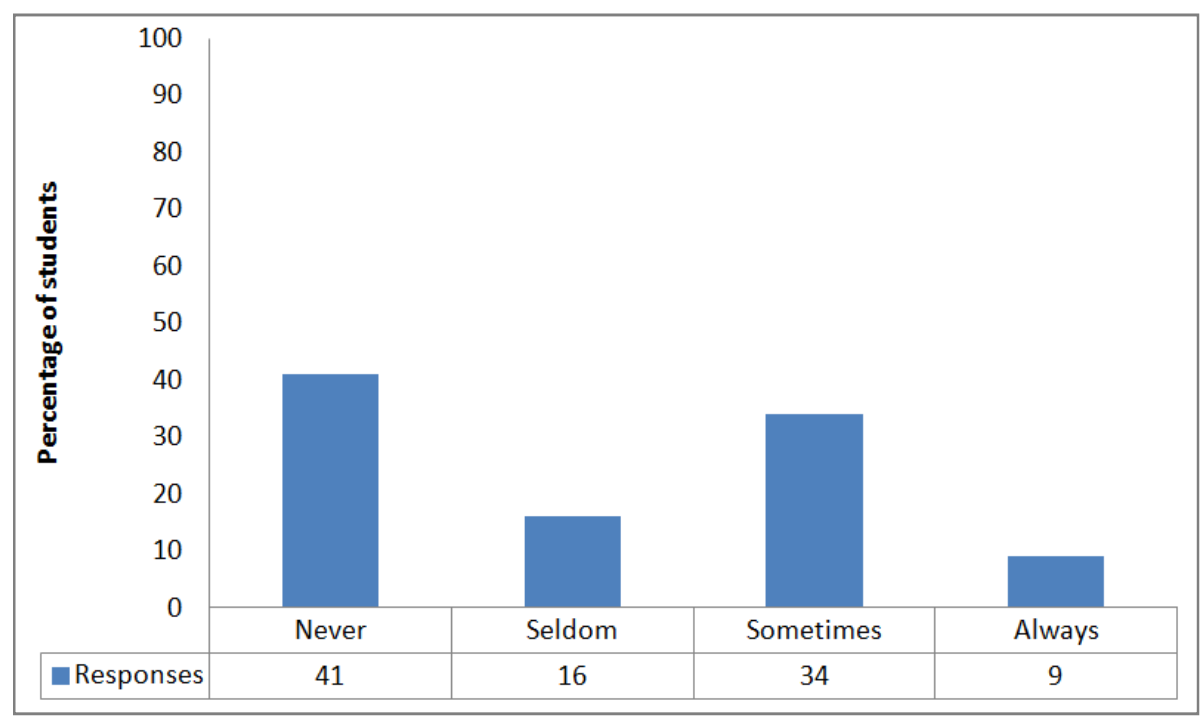

Figure (2). Responses frequency from the study cohort $(N=200)$ on frequent dieting during last year. 
Concerning attitude towards healthy lifestyle, $27 \%$ of the students noticed that they gained weight, $38 \%$ have lost weight and $35 \%$ were of the same body weight over the course of the past year (Figure 1).

Figure (2) shows that $41 \%$ of students had never diet, $34 \%$ admitted to diet sometimes, $16 \%$ seldom diet and $9 \%$ always diet.

Low fat diet, low calorie diet and low carbohydrate diet were followed for the purpose of weight reduction by $47 \%$, $29 \%$ and $9 \%$ of the students respectively as illustrated in Figure (3).

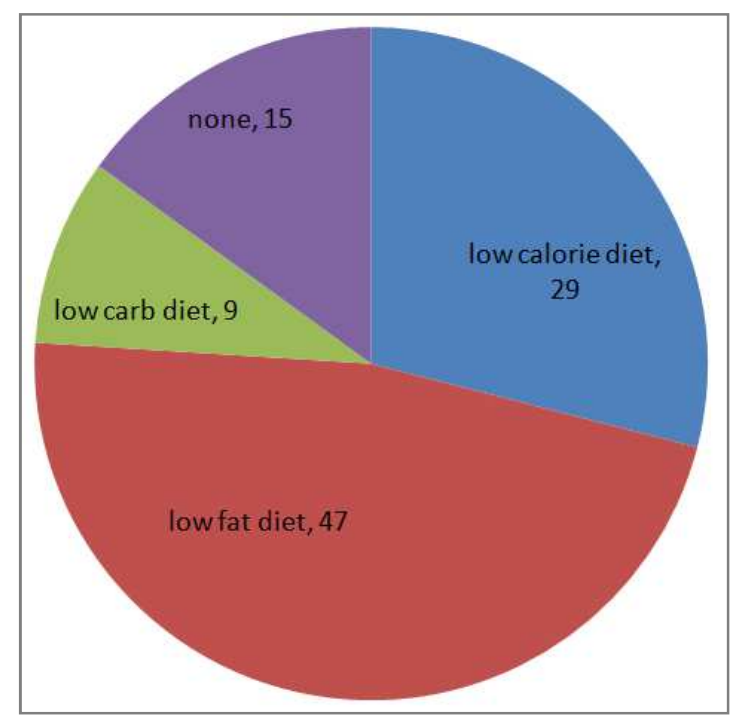

Figure (3). Type of diet pursued for weight reduction by the study cohort $(N=200)$. Available choices are: none, low calorie diet (one providing 800 1200 calories per day for an adult), low fat diet (i.e., one which provides fewer than $30 \%$ of energy from saturated fat (meats, dairy products) and should be low in cholesterol (less than $300 \mathrm{mg} / \mathrm{d}$ ) and trans fatty acids and rich in wholegrain, fresh fruits and vegetables, and legumes) and low-carb diet (one which provides less than $45 \%$ of energy as carbohydrates from simple sugars and rich in proteins (meat, poultry, fish and eggs), and some non-starchy vegetables).

Majority of students $(82 \%)$ responded that they never use weight reduction medications and herbal preparation as depicted in Figure (4).

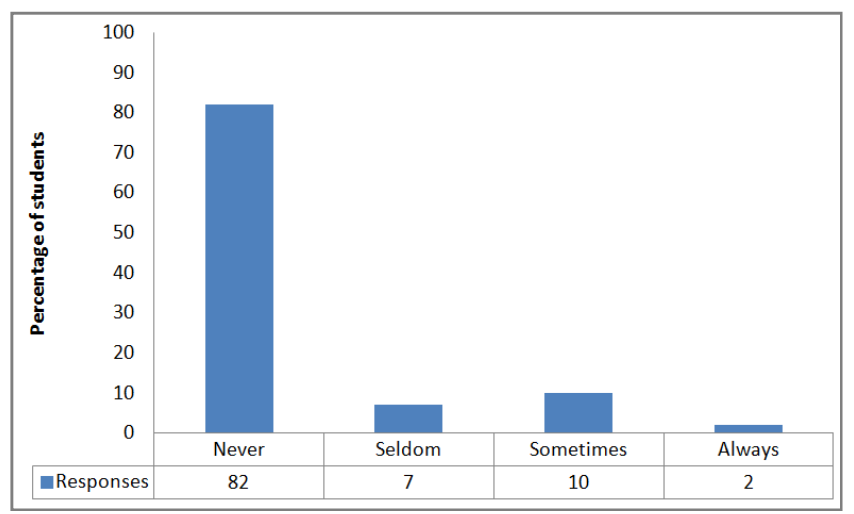

Figure (4). Responses frequency from the study cohort $(N=200)$ on the use of weight reduction medications and herbal preparation.

\section{Discussion}

This study aimed to evaluate nutrition knowledge, eating habits and overall perception regarding importance of healthy eating habits of medical students of KAU, KSA.

University life is potentially important target for the promotion of healthy lifestyle of the young adult population. A noteworthy hypothesis is that nutrition knowledge and attitude is more related to the field of study.

No gender-specific difference was noticed in terms of the students' nutritional knowledge and attitude, as no correlation with age was stated before in a similar study cohort [10]. Unlike previous results that reported the female students achieved better scores than male students on nutritional knowledge and attitude [11].

Some studies have shown that students are only slightly aware of nutrition issues and their knowledge and attitude are average [12]. Other studies have shown that medical students had a superior level of knowledge on health issues regarding diet, lifestyle and exercise and this was replicated in the current study [13]. This might be attributable to the fact that over one third of the study participants had completed studying the basic health sciences. Overall, most university students are not familiar with healthy foods needed for their body in different conditions [2][14] and need to have nutrition education programs [15].

Lack of health consciousness amongst the general student population has been observed in other studies where students were practicing unhealthy dietary habits and made inappropriate choices [16][17]. Nevertheless, medical students did not make an extra effort to choose a healthier lifestyle or to eat healthy food. This is consistent with pervious researches which showed that medical students had a greater knowledge on health issues and their implications, nonetheless they were not putting this knowledge into practice due to certain barriers [10].

Poor time management was the most commonly cited factor preventing achievement of a healthier lifestyle among our study cohort (Table 2). There was a large proportion of university students who perceive their lifestyles to be moderately or highly stressful and linked to lack of proper time management [8][18].

Decreased levels of physical activity and leisure are linked to increases in the prevalence of an overweight condition, obesity and diet related non-communicable diseases among young generations [19][20]. Nevertheless, our female students had mentioned different motivators to play, which reflect their wide knowledge about the benefits of exercise to both physical and mental health. Apparently the two main barriers mainly identified by the participants of most studies on similar populations were lack of time and stress (Table 2).

Most medical students claim not to have enough time to exercise and eat healthier meals due to the demands of their studies and clinical rotations in the respective wards [19][21]. Hence medical students are unable to translate knowledge 
into better practice. However, the use of time as barrier to exercise by young people is disturbing. One possibility is that time is not a true barrier, but rather an excuse for non participation.

About $65 \%$ of the study population reported weight fluctuation over the past year (Figure 2) and 59\% were inherent to frequent dieting with different rates (Figure 3). The majority $(85 \%)$ were following different diet regimens for weight reduction (Figure 4). Previous studies show that individuals that have basic nutrition knowledge and attitude apply these principles when selecting foods and also indicated that Food faddism is one among many influencing factors on student food choices [9][22]. Nutrition education as one of the important practical aspects of nutrition knowledge, plays an important role in raising public awareness and ultimately health of society [23].

Nutrition education programs may have important uses in studying the behavioral determinants of healthy eating patterns where an integrated measure of diet can be used as the outcome of interest [24]. They can also be used in monitoring and surveillance to assess how well people comply with dietary guidelines, to monitor trends in the population over time, and to target diet and nutrition messages for the public.

\section{Conclusion}

Overall most medical students were aware of the importance of healthy eating habits yet they were not practicing it adequately in their daily life. Improving nutrition knowledge, attitude and dietary practices through nutritional education may help to prevent many nutritionrelated diseases.

The results of our study may shed some light on the importance of establishing the evidence-based data for effective curriculum development on healthy eating, construction of health education materials for the prevention of non-communicable chronic diseases among young youth, and most of all, for the provision of nutrition education to the students for adoption of healthy eating among the medical and paramedical students.

\section{Acknowledgment}

The authors express their sincere gratitude to the students research support committee in the faculty of medicine, King Abdulaziz University. The authors thank all of the study participants. The authors are grateful for the assistance of the staff of physiology department, faculty of medicine, KAU during the data collection. The assistance of Ayman M Baabdullah and Ramiz I Baabdullah with male students interviews is highly appreciated. The authors are grateful to Prof Gordon Ferns for his critical comments on the manuscript draft. The authors declare no conflict of interest. The authors received no funding from an external source. All authors read and approved the final manuscript. Authors' contributions: Data collection and entry: HA, AZ, DA, MB,
NB. Overall concept and design, Statistical analysis, data interpretation and manuscript writing and drafting: EA.

\section{References}

[1] Green L and Kreuter M. Health Promotion Planning: An educational and ecological approach, 3rd ed. Educational and ecological assessment of factors affecting health-related behavior and environment. Mountain View, CA: Mayfiled 1999, pp152-157.

[2] Cotugna, N.; Connie, E.; Vickery, R.D.; Sheldon, M. Sports Nutrition for Young Athletes. Journal Scandinavia Nutrition 2005; 21(6): 323-328.

[3] O'Dea, A.J.; Abraham, S. Knowledge, beliefs, attitudes, and behaviors related to weight control, eating disorders, and body image in Australian trainee home economics and physical education teachers. Journal Nutrition Education 2001; 33(6): 332-340.

[4] Sakamaki R, Toyama K, Amamoto R, Liu CJ, Shinfuku N. Nutritional knowledge, food habits and health attitude of Chinese university students - a cross sectional study. Nutr J 2005; $4: 4$.

[5] Wardle J, Parmenter K and Waller J. Nutrition knowledge and food intake. Appetite 2000; 34(3): 269-275.

[6] Kanz N and Becker M. The health belief model: A decade later. Health education Quaterly 1984; 11(1): 1-47.

[7] Ortega RM, Redondo MR, Lopez-Sobaler AM, Quintas ME, Zamora MJ, Andres P, et al. Associations between obesity, breakfast-time food habits and intake of energy and nutrients in a group of elderly Madrid residents. J Am Coll Nutr 1996; 15: $65-72$.

[8] Webb E, Ashton CH, Kelly P, Kamah F. An update on British medical students' lifestyles. Med Educ 1998; 32: 325-31.

[9] Ruka, S., K. Toyama, R. Amamoto, Ch. Liu, and N. Shinfuku. Nutritional knowledge, food habits and health attitude of Chinese university students-a cross sectional study, J. Nutr., 2005; 4(4): 1475-1480.

[10] Georgia, S.; Guldan, Y.W.; Lin, Y.; Zhao, M.; Xiang, D.P.; Yang, L.; Long, F. Evaluation of a nutrition education activity for medical student in china. Asia Pacific Journal of Clinical Nutrition, 1993; 2(8): 71-76.

[11] Hendrie, G.A., J. Coveney, D. Cox. Exploring nutrition knowledge and the demographic variation in knowledge levels in an Australian community sample. Pub. Health. Nutr., 2008; 11(12): 1365-71.

[12] Lowry, R., D.A. Galuska, J.E. Fulton, H. Wechsler, L. Kann and J.L. Collins Jan. Physical activity and weight management goals and practices among US college students. Am. J. Prev. Med., 2000; 18: 18-27.

[13] Chang, S.L. Survey on health knowledge of college student in the middle area of Taiwan. J. Pub. Health., 1987; 14: 250-273.

[14] O'Dea, A. Jennifer. School-based health education strategies for the improvement of body image and prevention of eating problems. An overview of safe and successful interventions. J. Health Educ., 2004; 105(1): 11-33. 
[15] Robinson-O'Brien, R., N. Larson, D. Neumarkof-Sztainer, P. Hannan and M. Story. Characteristics and dietary patterns of adolescents who value eating locally grown, organic, nongenetically engineered and no processed food. J. Nutr. Educ. Behav., 2009; 41(1): 11-8.

[16] Carter AO, Elzubeir M, Abdulrazzaq YM, Revel AD, Townsend A. Health and lifestyle needs assessment of medical students in the United Arab Emirates. Med Teac 2003; 25: 492-6.

[17] Silliman K, Rodas-Fortier K, Neyman M. A Survey of Dietary and Exercise Habits and Perceived Barriers to Following a Healthy Lifestyle in a College Population. Californian J Health Promot 2004; 18: 281.

[18] Khawla M, Landman J, Musaiger A. Nutrition knowledge, attitudes and practices: a comparison between medical practitioners and medical students. Bahrain. Health Education 2003; 104 (2): 90-99.

[19] Troyer D, Ullrich IH, Yeater RA, Hopewell R. Physical activity and condition, dietary habits, and serum lipids in second-year medical students. J Am Coll Nutr 1990; 9: 303-7.
[20] Du S, Lu B, Zhai F, Popkin BM: A new stage of the nutrition transition in China. Public Health Nutr 2002; 5: 169-74.

[21] Conroy MB, Delichatsios HK, Haffler JP, Rigotti NA. Impact of preventive medicine and nutrition curriculum for medical students. Am J preventive medicine 2004; 27: 77-80.

[22] Read, M., \& Schlenker, E. D. Food selection patterns among the aged. In J. M. Smith (Ed.), Nutrition in Aging 1993;pp. 45-53. 2nd ed. St. Louis, MO: Mosby Inc.

[23] Harvey-Berino J, Hood V, Rourke J, Terrance T, Dorwaldt A, Secker-Walker R. Food preferences predict eating behavior of very young Mohawk children. J Am Diet Assoc. 1997; 97(7): 750-3.

[24] Rafferty AP, Anderson JV, McGee HB, Miller CE. A healthy diet indicator: quantifying compliance with the dietary guidelines using the BRFSS. Prev Med. 2002; 35: 9-15. 